\title{
That Look That Makes You Not Really Want to be There: How Neoliberalism and the War on Drugs Compromise Nursing Care of People Who Use Substances
}

\author{
Kathryn Hardill
}

Peterborough 360 Degree Nurse Practitioner-Led Clinic

Cite as: Hardill, K. (2019). That Look That Makes You Not Really Want to be There: How Neoliberalism and the War on Drugs Compromise Nursing Care of People Who Use Substances. Witness: The Canadian Journal of Critical Nursing Discourse, 1(1), 13-27. https://doi.org/10.25071/2291-5796.15

\begin{abstract}
Research conducted in 2016 explored the health care experiences of people who use illicit opioids in small Ontario urban and rural communities. Perspectives of participants who used opioids and of nurse participants were interpreted using Friere's critical social theory framework to explore sociopolitical, economic and ideological influences. Findings describe pervasive experiences of stigma, discrimination and inappropriate care. Exploration of why such negative experiences with nursing care might be so pervasive led to a consideration of the context of health care systems and in particular of the influences of neoliberalism and the impact of the global War on Drugs. Mitigation strategies to support contextualized nursing practice are outlined. Nurses are called upon to actively resist the pressures of these political forces by advocating for policy change including decriminalization.
\end{abstract}

Keywords: Critical social theory, Freire, Neoliberalism, Nursing care, Qualitative, War on Drugs

Over the last two decades, the illicit use of opioids, including prescription opioids, has risen significantly across Canada. In 2010, the College of Physicians and Surgeons of Ontario (CPSO) released a report on the opioid "public health crisis" in Ontario (CPSO, 2010, p. 5). In people aged 25 to 34 in Ontario, one of every eight deaths is opioid related (Gomes, Mamdani, Dhalla, Cornish, \& Paterson, 2014).

There is a paucity of research with people who use drugs outside of large urban centres. Barriers to care faced by those in small towns or rural communities include transportation costs, the lack of public transportation, lack of child care, fear about lack of confidentiality, and stigma (Canadian AIDS Society/Canadian Harm Reduction Network, 2007; Clay, 2007; Harvey, Shmied, Nicholls, \& Dahlen, 2015; Lloyd, 2010; Neale, Tompkins, \& Sheard, 2008;
Peterson et al., 2007). Gender and social exclusion amplify such barriers as stigmatization, stereotyping, racism, and policies that impair access to care (Carriere, 2008). Many studies report the presence of stigma and its role in creating barriers to obtaining health care, a number of which are Canadian studies (Gustafson, Goodyear \& Keogh, 2008; Jackson et al., 2010; Lang et al., 2013; McCutcheon \& Morrison, 2014; Pauly, McCall, Browne, Parker, \& Mollison, 2015; Wise-Harris et al., 2016).

Nurses' views of people who use substances include fear for their personal health and safety (Monks, Topping, \& Newell, 2012; Peckover \& Chidlaw, 2007); mutual distrust (Monks, Topping \& Newell, 2012); fear that some patients would not disclose their substance use, therefore compromising safe care; anger and frustration related to perceived 
manipulative, rude or disruptive behaviour; and disapproval of people seen as not taking responsibility for their health (Ford, 2011). Therapeutic relationships can be compromised when people who use substances are characterized as drug seeking, lacking in personal responsibility, or undeserving of care (Pauly, Goldstone, McCall, Gold, \& Payne, 2007). Nurses may lack sufficient education about substance use, including injection drug use (Ford, 2010; 2011; Lang et al., 2013). Nurses' lack of knowledge of harm reduction is a gap (Ford, 2010; 2011) and there appears to be a disconnect between a pro-harm reduction position of some provincial and national nursing organizations and the lack of knowledge and implementation of harm reduction by nurses in Canada (The Canadian Nurses Association [CNA], 2011; The Registered Nurses' Association of Ontario [RNAO], 2015). Some nurse researchers identify nurses as wellpositioned to lead harm reduction-informed research and advocacy and some have proposed models of care to address inequitable access to health care experienced by people who use illicit substances (Pauly, 2008a; 2008b; Smye, Browne, Varcoe, \& Josewski, 2011). Pauly et al. (2015) propose a model of "cultural safety" to address inequitable health care and access for people experiencing discrimination related to illicit drug use, poverty and homelessness.

In 2016, I conducted research on the health care experiences of people who use illicit opioids in a small urban community in Ontario, Canada. Using the qualitative constructivist paradigm, perspectives of participants who used opioids and those of nurse participants were interpreted using Freire's critical social theory framework to explore sociopolitical, economic and ideological influences. People who used opioids recounted experiences of nursing care that was judgmental, stigmatizing and made them feel worse. Nurses recounted experiences of feeling as though they could not trust patients who used drugs, that such patients brought on their own health issues and that substance use was a choice that could be made or unmade. In this paper I will present the key study findings and discuss these in the context of the influences of neoliberalism and the global "War on Drugs," which contribute to creating a divide implicitly required by neoliberalism between people who use opioids and the nurses who care for them. Recommendations for contextualized nursing practice and policy change are discussed as mitigation strategies.

\section{Research Design and Methodology}

WITNESS
This research was conducted using the epistemological lens of Freire's (1970) critical social theory (CST) framework, founded on the assumption that what is perceived to be real is shaped by sociopolitical, economic, cultural and ideological contexts. Methodology was situated in interpretive description, developed to provide an inductive, analytic approach to generating qualitative nursing knowledge which answers complex, contextual questions (Thorne et al., 1997). The epistemological underpinnings of interpretive description are also rooted in the beliefs that there are multiple complex constructed realities; and that researcher and participant engage in dialogic interaction which is reciprocal and mutually influential (Thorne et al., 2004). Ethics approval was obtained from York University in Toronto, Canada.

Field work was conducted in a small Southern Ontario city with a population just under 80,000 people. Participants who used opioids were interviewed in a community-based harm reduction agency. Purposive sampling was used in cooperation with agency staff to identify and recruit eligible participants aged 19 and over and then snowball sampling was used to recruit the others on site. 10 participants currently using opioids by any route at least once monthly for at least six months were included in the data analysis. Prospective participants were excluded from participation if they had been under my nursing care in the past two years. Five participants identified as female and five as male ranging in age from 25 to 60 (average age being 39.5 years). Six participants identified as White/Caucasian and four identified as Indigenous (First Nations or Metis). Seven lived in rental housing and three lived in an emergency shelter. Five were receiving provincial disability benefits; four were receiving municipal social assistance benefits; and one was receiving federal disability pension benefits. One person reported a monthly income of less than $\$ 500$; five people reported a monthly income between $\$ 501$ and $\$ 1000$; and four people reported a monthly income between $\$ 1001$ and $\$ 1500$. Five people had been using opioids for more than ten years; three people for five to less than ten years; one person for one to less than two years; and one person for 6 months to less than 1 year. Six people reported daily opioid use in the previous 30-day period; three reported using opioids several times weekly in the previous 30-day period; one person reported using opioids several times in the past month; and one person report not having used opioids in the past 30 days. Nine people reported having ingested opioids orally as well as injecting opioids and five people reported having inhaled (snorted) crushed opioids. Eight people reported injection as their preferred method. Nine 
participants reported controlled release hydromorphone as their opioid of choice.

A cross-section of six nurse participants was recruited within the same geographic area. Six Registered Nurses or Nurse Practitioners were interviewed. The average length of time in nursing practice was 21.8 years. The primary practice setting for four participants was an emergency department; one worked in a primary health care setting; one worked in a specialty clinic and one participant had a part time inpatient/critical care practice setting in addition to their primary practice setting. Participants had practised in their current setting from three to nineteen years. Three had Registered Nurse diplomas; two had baccalaureate degrees in nursing; and one had a Masters' degree in nursing. Four were Registered Nurses and two were Nurse Practitioners.

Interviews were conducted in a private room or, for some nurse participants, by telephone. Interviews were audiotaped with permission and transcribed. Participants who used opioids were reimbursed for their time with $\$ 20$ cash after completing the first interview and $\$ 10$ cash after the follow up interview (which was typically shorter in duration). Nurse participants were reimbursed with a $\$ 10$ gift card.

After obtaining informed consent, participants who used opioids were engaged in open-ended, semistructured, conversational interviews to explore their experiences of health care. Because of the likelihood that participants who used opioids might disclose their involvement with illegal activities, there was a remote but possible risk that third parties might wish to gain access to the data. To extend the fullest protection possible for participants who used opioids, no identifying information was recorded and consent was obtained verbally. Once these interviews were completed and transcribed, open-ended, semistructured conversational interviews were conducted with nurse participants in order to understand the perspectives of nurses caring for people who use opioids in small communities and to view the issues articulated by people who use opioids through a nursing lens.

Reflexive field notes were written immediately after each interview. Each participant who used opioids was asked to return for a follow up interview on one of two specific dates. Of the ten participants included in the data set, seven returned for a second interview. After transcribing the first interviews, a preliminary thematic analysis of each transcript followed by all transcripts was conducted to determine common themes. In the second interviews, preliminary WITNESS interpretations were reviewed with participants to assess interpretive validity. Because of the possibility that attendance by participants who use illicit opioids at the follow up interviews might be less than $100 \%$ due to attrition a strategy was borrowed from Smye, Browne, Varcoe and Josewski's (2011) study which reviewed interpretations for accuracy and interpretive validity with a sub-set of participants.

Using Benner's (1994) analytic method the data was searched for paradigm cases, thematic analysis and exemplars. Coding was purposely avoided until many weeks into the process. Note was taken of similar themes and broad categories and analysis moved back and forth from individual stories to larger patterns and themes. Once over-arching themes and sub-themes were generated Fontana's (2004) foundational processes of critique, context (historical, political, socioeconomic), politics (exposing unequal power relationships), emancipatory intent (looking for possibilities for change), democratic structure, dialectic analysis, and reflexivity were used to to inform analysis and extrapolation to potential explanations, conclusions and recommendations.

Credibility was established through triangulation of data from multiple sources, by transcribing interviews and field notes, and by reviewing all transcripts for similarities and preliminary themes and patterns. Transferability was facilitated by collecting data from both groups of participants to create a "dense description" of the study populations as well as the geographic boundaries of the study. Dependability was established through the creation of a detailed description of study decision making including the overall purpose; research questions; participant selection and recruitment; data collection; interview guides; as well as reflexive notes documenting my questions, concerns about pitfalls and strategies to avoid them as much as possible; and a detailed chronological audit trail documenting analytical decision-making. Confirmability was established through member checking via a follow up interview (for seven of ten participants who used opioids) during which their individual first transcripts were reviewed for accuracy as well as checking whether my preliminary analysis reflected what they had intended to convey. Confirmability was also supported through reflexivity including writing of field notes after each interview articulating personal reactions, biases and insights and again following transcription of each interview in the comments pane.

\section{Findings}


The overarching findings can be summed up this way: people who use opioids want to be treated with respect and compassion by nurses; and nurses want to connect with their patients and provide excellent care to them. Myriad factors contribute to a significant disconnect between the two groups which has negative consequences for nurses and for people who use substances. People who use substances may experience frustration, inadequate care, lack of care, and misdiagnosis. They may leave the health care setting feeling worse than they did on arrival and may delay or avoid seeking care in the future. Nurses may experience frustration, helplessness, reduced role fulfillment, moral distress, compassion fatigue and burnout. Many of the findings of this study are supported in the international and Canadian literature on the health care experiences of people who use substances, such as the prevalence of stigma, discrimination and judgment by health care providers including nurses. Also supported were findings that some nurses find people who use substances challenging to look after and feel they lack sufficient education on substance use. Pseudonyms are used for all participants. Eight key analytical themes emerged:

\section{"It's Like A Switch Gets Flipped"}

A prominent theme articulated by participants who used opioids was that of an abrupt attitudinal change by some nurses on discovery of (or suspicion about) someone's opioid use. Some participants who used opioids likened this to a switch being flipped. Frank described it as "it's like day and night with the attitude...they think you're just a waste of time." Chase echoed the sentiments of other participants who used opioids in identifying how they knew when the switch had been flipped: "...they give you that look that makes you not really want to be there." Participants interpreted this look as conveying "disgust" [Casey]; "like you're not a person" [Joanne]; "you're the scum of the earth" [Frank]; "that you're a screw up and you're less than them, you're less of a person." [Chase].

\section{Nurses Lack Accurate Knowledge about Substance Use}

Participants who used opioids frequently commented that nurses did not understand substance use or people who use substances. Nurses reported that neither their basic nursing education nor their ongoing professional development provided sufficient education on substance use. Participants who used opioids noted that these gaps included minimizing the severity of the symptoms of opioid withdrawal, not understanding the presence of underlying mental health issues in people who use substances; and not being aware of the role of trauma and adverse early life experiences in the etiology of problematic substance use.

This lack of knowledge can affect patient care. For example, when nurses minimize the severity of withdrawal symptoms, it may convey the message that people who have experienced opioid withdrawal are viewed as catastrophizing or malingering; that they may be using these symptoms as a rationale for obtaining opioids; or perhaps that they deserve this suffering. As Steve said, he has heard this message from health care providers numerous times: "you got yourself in that position, and don't be crying to us, right? " Some nurses held the view that substance use was a "choice" which could be made or un-made. Sue was of the opinion that when patients have overdosed and require resuscitation because they are unconscious, that this lack of awareness of how close they have been to death supported their ongoing substance use: "I think that basically they continue with the abuse to themselves because they have no recollection of it!"

\section{Reciprocal Mistrust}

A significant finding in both groups of participants is that of pervasive lack of trust of the other. Disclosing one's opioid use often led to not being believed by health care providers. Some participants who used opioids concluded they might be better off not disclosing their use. Chase attended hospital with a serious infection in his hands from injecting opioids. Because of opioid-induced constipation, he was in the washroom for a long time. This caused the nursing staff to believe he was using illicit opioids in the washroom:

I had a blood infection and my hands swelled to the size of balloons... and I went to...use the washroom, and when you're really heavy into opioids, it's really hard for you to have a bowel movement, so I was in there for a bit, and the nurses came and grabbed me and they had just hooked me up to an IV for antibiotics...so they came up to me and said basically you're being discharged from the hospital because you were using in the bathroom. They assumed that I was shooting up in their bathroom, so they told me basically I had to leave. I in turn kind of retaliated to that by putting up a front, like "what the hell?" like kind of being verbal with them, like kind of aggressive? Which I probably shouldn't have done, but I felt very scared because they had just told me I could 
have died, and now they were telling me I have to take this antibiotic out of my body, and...I was scared, right?

Nurses described wanting to believe their patients but were cognizant of some people's reluctance to disclose illicit substance use. Nurses were concerned that nondisclosure of opioid use might lead to dire consequences for patients if additional opioids were administered. Nurses were also concerned that people who use injection opioids might use intravenous access devices to inject their illicit drugs and believed that this would not be safe. One nurse recalled the need for enhanced surveillance by nurses of patients known to be opioid users once a venous access device was inserted, especially if those patients left the unit. Brian described feeling the need to "watch them like a hawk...because you never knew what they would do when they (left) the unit."

This experience of mutual mistrust becomes in some regards an endless feedback loop. Patients may not trust that they will not be stigmatized for disclosing their opioid use, so they may withhold this information. Nurses suspect patients of non-disclosure and then, when they discover opioid use through, for example, a urine toxicity screen, feel they are correct to mistrust patients.

\section{Experience Matters - But Self-Taught May Not Always Be Helpful}

Some nurses indicated that they compensated for their lack of education on substance use by learning how to provide care to people who use substances on their own or through their nursing experience. Although some nurses felt experience enabled them to more confidently care for people who use substances, being self-taught was not always helpful as nurses sometimes learned either inaccurate information or they simply learned how to conceal their true feelings about patients who use substances. James reflected on how his care has changed with experience. He recalled nurses who were avoidant, rude or judgmental towards patients who use substances and noted: "...there was a time in my career when I did that. But I think over the...years...I've kind of matured...(and) put on a façade of professionalism so that the patient does not know what you think of them." This may be a means to cope with the challenges of caring for people who use substances for nurses who would use a different way of relating if they had the skills, knowledge and institutional support to do so.

The Myth of Normal
Several nurses articulated the idea that drug use was not "normal" nor something that "normal" people engaged in. A story James recounted was of a young woman whom he had cared for over a long period of time, who eventually died of drug-related complications. James described this patient as a "normal kid" from a "normal" family. He had met the young woman's mom and related to her and to the young woman who seemed much like James and James' family. Sue told a story of connecting with a young woman who was her age who struggled with addiction. The similarities between this young woman and Sue prompted Sue to be grateful she had gone down "...the right path in life," having made the correct "choice" not to use drugs. Lorraine told a story was of a young woman who did not disclose her methadone use prior to being given conscious sedation drugs which affected her adversely. Lorraine said "...she went to university, she... was middle class - we had no reason to suspect (she was on methadone)." This would seem to indicate that some nurses believe the following:

a) Drug use indicates a deviation from the normal life path;

b) People who use drugs can usually be visibly identified;

c) People who use drugs are not usually middle class;

d) People who use drugs are not usually a lot like me.

\section{Witnessing the Decline}

Some nurses remarked on how difficult it is to witness the declining health of someone who uses opioids and feeling helpless to intervene or make any difference to that trajectory. Several nurses expressed frustration with seeing the same patients repeatedly for the same issues related to their opioid use and not being able to offer any resources or help. Partly this frustration was related to the lack of mental health and addictions resources in a small community and partly because of not knowing what practical assistance to offer. It was also articulated that it was emotionally difficult to watch people get more and more unwell and eventually die: “...there's a point where they just become terminal and they are past whatever help you can give them..." [Jennifer]. Nurse participants frequently stated that they felt frustrated and helpless when caring for people who use opioids. Some expressed negative characterizations of people who use substances and some expressed disgust with nursing colleagues who made disparaging remarks about people who use substances. It could be argued that caring for people who use opioids may cause 
nurses to experience moral distress on several levels: not feeling competent in their knowledge of substance use; not knowing about interventions to offer that would make a difference; not being able to link patients to resources that do not exist in smaller communities; and caring for patients they perceived negatively

\section{How Dare You? Caring for Women is Different}

When asked about their impressions and experiences of caring for women who use opioids, several nurses agreed that women's reproductive potential conferred an additional layer of expectations on women which were not conferred on men who might be parents. They expressed concern and in some cases judgment related to possible in-utero fetal effects. Nurses spoke of trying not to be judgmental but finding it difficult not to think about what maternal opioid use might be doing to a fetus. Some nurses expressed conflicting feelings of not wanting to judge someone but having judgmental feelings nonetheless: "I mean it ups the ante, right?... as a health practitioner, you'd like to say you never judge anyone, but honestly you kinda do..." [Brian]. Jennifer recalled how some nurses adopt an attitude towards a pregnant woman using opioids of "how dare you" do this to your unborn child. Lorraine remarked: "...we do see the babes coming in that are on the withdrawal protocol, and I don't think there's really enough research on that to really - I don't know...I try not to be judgmental about that in my practice, but it's always in the back of your head what's happening to baby..."

\section{In a Small Town the Stigma Lasts Forever}

Several participants who used opioids described the challenges inherent in living in a small community because the pool of health care providers is small and you become known as someone who uses or who has used illicit opioids in the past. This label becomes one's primary identifier and may stick to a person forever, even if someone is no longer using opioids. Being labelled as a person who uses illicit substances may be communicated informally from provider to provider and be applied to one's family members, appropriately or not (Hardill, 2011). Some participants who used opioids noted that if you are known to be someone who uses illicit opioids, some health care providers assume the reason for every visit is to obtain opioids, even when this is not true. There is little anonymity as Steve noted: "... and (this town) is so small, everybody knows everybody in the town...(but) they don't know why you're on drugs - they don't know anything about my life at all, other than the fact they might have gone to high school with me..."

In many ways the "switch" metaphor helps to explain many of the other key findings. My analysis of the "switch" is that the creation of authentic caring relationships by nurses (which usually defaults to the "on" position) is turned down or even switched off, like a dimmer light switch, with gradations of reduced caring or greater disengagement from patients depending on nurse and patient factors and the particular health care context. Regardless of how far the switch is turned down, the result is the provision of care which may be more aptly described as a series of disengaged nursing tasks.

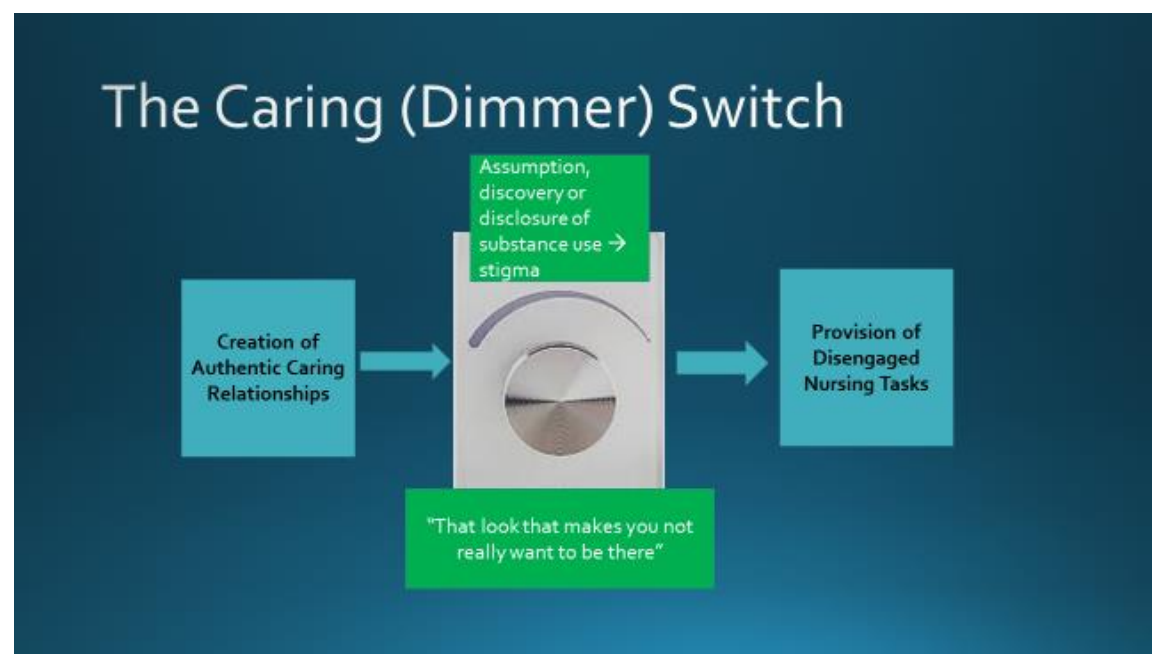




\section{Figure 1. The Caring Switch}

\section{What triggers the switch to be flipped?}

Disclosure by participants who used opioids of any one or more of these issues to a nurse or other health care provider frequently resulted in an abrupt attitude change by some nurses which can be described as flipping off the (caring) switch. Notably, this theme of experiencing stigma related to one's substance use arose repeatedly, regardless of what question I posed and even when I was not specifically asking about it. It appears that the primary trigger for the switch to be flipped is stigma - related to one or more of the intersecting stigmatizing attributes which may characterize people who use opioids including having $\mathrm{HIV}$ or Hepatitis C infections; being seen to be at risk for contracting and transmitting HIV or Hepatitis $\mathrm{C}$ infections; being tested for these infections; being on methadone; engaging in non-traditional ways of making money such as sex work or selling drugs; having a health issue that arose as a direct consequence of drug use such as an abscess or an overdose; and, widely perceived as the most stigmatizing of all, being someone who injects opioids. These findings are consistent with those from other international jurisdictions (Ahern et al. 2007; Butt, 2008; Harris, 2009) and from other Canadian jurisdictions (Gustafson et al., 2008; Jackson et al., 2010; Lang et al., 2013; McCutcheon \& Morrison, 2014; WiseHarris et al., 2016).

Nurses' perceptions of the switch being flipped were generally quite different than those of participants who used opioids. Some nurses disputed the existence of the switch, suggesting that everyone received the same treatment regardless of their drug use status. Perhaps these nurses were referring to patients receiving equivalent interventions, but perhaps being unaware or disregarding differences in attitude towards people who use opioids. One nurse suggested knowing about someone's opioid use could expand the diagnostic evaluation to encompass a broader set of differential diagnoses.

Nurse participants identified that caring for people who use illicit opioids was frustrating, difficult, and challenging because of their sometimes perceived disruptive and otherwise "bad" or "not nice" behaviour including agitation; because of sometimes co-occurring mental health issues manifesting symptoms such as paranoia; because of not being sure if such patients were trustworthy; and because of feeling helpless to meaningfully intervene. As well, nurses expressed frustration and judgment at repeat

WITNESS visits to an emergency department for the same issues over and over; for being seen to bring on their own health issues; for being assumed to be narcoticseeking; and for taking time and attention away from other patients.

\section{"The look" - how you know when the switch has been flipped.}

Casey remarked, “...the way they look at you, it's just kind of in disgust." Several participants described experiencing a "look" from nurses, which they described as conveying disgust. This unmistakeable look made them feel "like you're not a person" [Joanne] or like "you're the scum of the earth" [Frank]. Chase noted "...once they see your arms or wherever you shoot up, they give you that look that makes you not really want to be there...basically that you're a screw up and you're less than them, you're less of a person."

Participants who use substances identified that once this switch was flipped, they experienced discrimination, judgment, frustration and blame for their health issues by health care providers including nurses. John, who had a lengthy opioid-using history and countless health care experiences over decades remarked that discrimination was a standard expectation for him upon entry into a health care setting. Participants who used opioids described being made to wait longer for care, being given less information ("the conversation stops flowing" [Joanne]) and being admonished and blamed for having damaged veins.

This notion of a switch which can turn off empathetic caring begs the question - why have one? What could be the purpose? In what circumstances would it be used?

\section{The desire to minimize risks.}

The nursing literature suggests that nurses may distance themselves from patients who use substances to protect themselves from perceived risks to their safety and the desire to reduce disruptive behaviour. Peckover and Chidlaw (2007) found that British home visiting nurses working with people who use substances dealt with fear for their own safety by reducing visit duration and focusing solely on the specific tasks to be performed at the visit. Ford's (2011) study of Australian nurses caring for people with substance use issues found that some identified 
challenges in interacting with patients related to perceived manipulative and irresponsible behaviours. Monks et al. (2012) found that nurses working on an inpatient unit minimized contact with and implemented a detached manner of providing care to patients who use substances to minimize the risks of disruption and violence.

\section{Lack of knowledge about substance use and harm reduction.}

Ford (2010) described constrained nursing care of people who use substances when nurses lacked adequate knowledge about substance use and when they had limited institutional support for their role. Ford (2010) suggests that nurses' beliefs may mirror stereotypes held by the general population - a finding also reported by Harling and Turner (2011) with respect to Australian student nurses and Lang et al. (2013) in Saskatoon, Canada. In the Canadian context Smye et al. (2011) suggest harm reduction strategies may provide nurses a means to understand intersectional experiences of oppression while Pauly (2008a, 2008b) suggests harm reduction strategies might provide nurses with practical interventions allowing them to avoid moral judgments and move away from stigmatization.

\section{Replicating sociocultural beliefs about substance use.}

Pauly et al. (2007) observed that nurse-patient therapeutic relationships were hindered when people who use substances were characterized as irresponsible or undeserving of care. Morgan (2014) suggests, like Ford (2010), Harling and Turner (2011) and Lang et al. (2013) that nurses may be subject to the general socialization processes at work that cause them to unwittingly perpetuate societal labels which stigmatize and marginalize people who use substances, placing them in the category of undeserving of care. Some nurse participants did not find people who use substances to be trustworthy or expressed surprise if someone who used substances appeared to be from a "normal" background. Certainly, participants who used opioids experienced pervasive stigma for numerous reasons which persisted over time.

\section{Compassion fatigue.}

First described by Joinson (1992), compassion fatigue describes situations in which nurses and other caring professionals "turn off" their feelings or experience helplessness and anger in response to the stress of caring for people in a variety of challenging circumstances. Nurse participants articulated the frustration they felt dealing with the sometimeschallenging behaviours of people who use opioids. They also spoke of the difficulties they experienced witnessing patients decline and feeling helpless to intervene to change the outcome. Turning off the caring switch could be considered a coping strategy nurses might use in the context of compassion fatigue triggered by frustration and helplessness associated with caring for people who use opioids.

\section{Discussion}

A fundamental concern of nursing is compassionate, whole-person care of human beings. The epistemological lens of Friere's (1970) critical social theory framework was used to try to understand how the health care experiences of people who use illicit opioids in small towns and rural communities could be influenced by sociopolitical, economic, cultural and ideological contexts. Contemplating the sociopolitical influences on Canadian nursing practice, I considered whether adherence to the so-called "war on drugs" ideology regarding illicit drug use, which has been favoured by many Canadian legislators, might be reflected in the manner in which some nurses treat people who use drugs? Might mainstream ideological beliefs about drug use held by nurses in some way encourage or condone discriminatory treatment by nurses? How has the rise of neoliberalism exerted its influences on health care systems, on nursing, and on individuals? When considering these contextual influences, I began to see how the key findings of my research might fit into these larger sociopolitical contexts - in particular, stigmatization; reciprocal mistrust between nurses and people who use substances; the ways nurses used experience and selflearning to cope with the lack of education on substance use; the ways nurses "othered" people who use substances by invoking a false notion of deviance; and the divide in understanding which separates nurses and people who use substances. I began to understand that the powerful sociopolitical and economic global forces of neoliberalism profoundly affect nursing relationships at the micro-level.

The rise of global neoliberal economic policies in the 1970s coincided with the burgeoning world debt crisis during which the International Monetary Fund (IMF) and the World Bank gave loans to heavily indebted countries on the condition that they privatise state assets, liberalize taxation to benefit foreign investment and loosen tariff restrictions to rapidly facilitate globalization of trade. Central to these policy changes were reductions in social spending by governments which led to global increases in poverty and inequality 
(Labonte \& Stuckler, 2016). The rise of neoliberalism was accompanied by the dawn of the War on Drugs, a term infamously coined by former American President Richard Nixon in the 1970s. One of the most serious consequences of the decades-long War on Drugs has been the stigmatization of people who use substances, which clearly has been profoundly successful in doing so. These pervasive effects were hugely apparent in the small- town setting of this study. Stigma was a prominent finding and consistent with many other Canadian and international sources (Gustafson et al., 2008; Harvey et al. 2015; Jackson et al. 2010; Lang et al. 2013; McCutcheon and Morrison 2014; and Pauly et al. 2015).

It can be argued that Canadian policies which criminalize the use of many psychoactive substances create a climate within which substance use is considered a deviation from social norms. People who use psychoactive substances frequently have criminal records which further entrenches their characterization as deviant and contributes to stigma as well as creating practical limitations on factors such as movement between legal jurisdictions and on employability. Incarceration further marginalizes people and often interrupts any meaningful consistent health care relationships. Further, these legal policies and discriminatory enforcement practices uphold the status quo and the hegemony of dominant groups by targeting low income people, Indigenous people and other people of colour and have been tied directly to Canada's embrace of the War on Drugs (Lawrence \& Williams, 2006).

The ongoing legacy of the War on Drugs in Canada includes a sociopolitical climate which is hostile to harm reduction (Carter, 2013). Although major urban centres in Ontario have some harm reduction programming there is little available in small towns and rural communities. This has serious health consequences for people who use drugs because they may not have access to supplies, equipment and education to help them reduce the risks of using drugs. It also has consequences for nurses because of their feelings of frustration and helplessness at not having any practical assistance to offer people who use substances.

An important feature of neoliberal ideology is the notion that individuals freely make choices in their lives. It assumes an egalitarian "level playing field" environment where everyone has equal opportunities. Health care "consumers" can choose health although as Moore and Fraser (2006) point out, there is no acknowledgement that choice may be constrained nor is there a discourse that questions the epidemiologic WITNESS validity of the idea that healthy choices even matter, in the context of inequitable access to the social determinants of health. Consistent with the neoliberal belief that individuals are responsible for the choices they make, some nurses held the view that substance use was a "choice" which could be made or un-made. Sue, for example, thought that if patients who had overdosed and nearly died could see how close to death they had been, this knowledge would help them make the (presumably more rational) choice to stop using. Sue also recognized that while she felt empathy for the difficult situation people who use opioids are in, she also struggled with being unable to understand why they would continue: "I think there's a lot of empathy, but also you're like, man, there's help out there, what are you doing?" This lack of understanding was common among nurse participants. Pauly et al. (2015) found similar results and argued that viewing illicit drug use as an individual shortcoming is a common belief arising out of dominant neoliberal perspectives on substance use in Canada and North America.

Also consistent with the decontextualized neoliberal view that people freely choose to use opioids is the corollary finding identified by participants who used opioids that nurses lacked knowledge of the underlying reasons for substance use. People who use opioids observed that nurses frequently had no idea why they had started using opioids and why they used every day. Some nurses remarked that patients who use opioids sometimes had remote and recent experiences of assault and violence but they stopped short of articulating a direct cause and effect link between a history of trauma and substance use, despite the robust body of evidence which exists (Anda et al., 2006; Cosden et al., 2015; Giordano et al., 2016; Sandford et al., 2014).

Neoliberal thought implies that if people make unhealthy choices which are interpreted in a manner which completely excises them from any personal or historical context of trauma, racism, colonization, male violence, pervasive sexism and structural poverty and inequity, then they are to blame for their problems and they deserve what consequences they experience. Nurse participants identified that caring for people who use illicit opioids was challenging for a variety of reasons including: frustration at repeat visits to an emergency department for the same issues over and over; for being seen to bring on their own health issues as a result of their drug use; for being assumed to be narcotic-seeking; and for taking time and attention away from other patients (implying that they were less deserving of care). Pauly et al. (2007) observed that nurses sometimes characterized people who use 
substances as undeserving of care and this compromised nurse-patient relationships.

Recalling Friere (1970) who reminds us that “...the oppressor minority...cannot permit itself the luxury of tolerating the unification of the people" (p. 141), we can see through this critical social theory lens that neoliberalism does not merely create divisions between people, it requires them. They are intentional - reinforced by pervasive misinformation messaging about the deviance, irrationality, dangerousness and difference of others. Health care systems provide a microcosm for the replication of social relations of power (Neale et al., 2008) which represents one of countless bricks in the neoliberal foundation. Thus, the vast gulf in understanding between nurses and people who use substances begins to make contextual sense.

Looking through a critical social theory lens allows us to see the myriad ways neoliberal beliefs and policies influence health, health care systems, nurses and patients. These influences occur at the macro-level and are then acted out in individual nurse-patient interactions at the micro-level. Neoliberalism creates and requires the existence of a wide range of stigmatized "others," including low income people who use substances - who are widely perceived as morally suspect, untrustworthy, potentially infectious criminals who may engage in reprehensible activities to make money to enable themselves to continue to make terrible choices. Even the most caring of nurses, as members of society, take up and internalize these messages. Nurses also work in systems affected by neoliberal policies which make that work challenging and difficult and constrained by powerful structural forces of which they may be unaware.

\section{Limitations}

Demographics of participants who used opioids were less heterogeneous than they might have been using different sampling strategies with race being limited to either White or Indigenous origins. These participants' experiences may not be reflective of those from racialized or other racialized groups. It may reflect even more pronounced stigma affecting other racial groups in small communities that they were not strongly represented in the harm reduction service where interviews occurred. Others not represented were transgender people whose experiences may also have been different. No inquiry was made about sexual identity which may have had some further independent impact on participants' experiences of stigma and discrimination. All nurse participants were working in a small city in either a small community hospital, primary care clinic or specialty clinic although some of them may have lived in more rural locations. None were recruited from a rural or remote setting which might have resulted in differing perspectives. Limited hours of operation at the harm reduction agency's more rural satellite offices presented practical limitations to inclusion as interview sites.

\section{Resisting the Impacts of Neoliberalism Using Contextual Responses}

The suggestion by Neale et al. (2008) that interactions between health care providers and patients replicate social relations of power, giving health care providers the power to marginalize or exclude clients they deem 'difficult' or 'disruptive' and to facilitate access to those they deem 'normal' or 'deserving' or 'compliant' is instructive when exploring the health care experiences of people who use opioids in small communities. The divide between people who use illicit opioids and the nurses who care for them is caused by powerful structural dynamics. As Thorne (2008) reminds us, interpretive description requires that research interpretations be brought into the context of nursing practice, characterized as it is by complex sociopolitical and ideological influences, in order that we might alter the perspective through which the phenomena are generally viewed. This perspective-altering is necessary given what we know about the impact of negative health care experiences on the health of people who use illicit substances.

Contextualized nursing practice is patient-centred and pragmatic. It creates a climate of acceptance and compassion which supports honest disclosure by patients. Nurses must advocate for and, more importantly, managers of nurses must ensure workplace supports for implementation of contextualizing strategies such as these:

\section{Embrace the concept of trauma-informed nursing.}

Improved understanding of substance use and care can result from trauma-informed practice, policies and procedures, which are based on the core principles of acknowledgement of the pervasive nature of trauma; safety; trust; choice and control; compassion (including self-compassion); collaboration; and a strengths-based approach (Canadian Centre on Substance Abuse, 2014; Klinic Community Health Centre, 2013). Importantly, being trauma-informed profoundly shifts the perspective from asking patients "What is wrong with you?" to asking, "What has happened to you?" (Klinic Community Health Centre, 2013, p. 16). 


\section{Embrace a cultural safety model.}

Originally developed by Indigenous nurse scholars in New Zealand as a means of providing more respectful care to Indigenous populations (Kearns, Dyck \& Robinson, 1996; Ramdsen, 2000), cultural safety has been embraced by some in Canada (McNeil, Kerr, Pauly, Wood \& Small, 2015; Pauly et al., 2015) as a way to consider structural inequities and power imbalances and their roles in creating inequitable access and treatment within health care settings. Further these Canadian scholars have suggested the model can be applied to mitigate the effects of stigma, discrimination and inequity affecting the lives of marginalized people who use substances. Pauly et al. (2015) propose a model of cultural safety to bridge the gap between people who use illicit drugs (who characterize the health care system as unsafe due to stigmatization) and those caring for them. McNeil et al. (2015) advocate for the adoption of a cultural safety model also on the basis that it supports patient-centred care which "structurally vulnerable" groups such as criminalized or racialized people and including people who use illicit drugs do not receive equitably (p. 686).

\section{Embrace a relational inquiry practice model.}

Doane and Varcoe $(2007 ; 2015)$ have described a relational inquiry practice model to help nurses navigate the increasingly challenging contexts of nursing relationships and enactment of nursing values. A relational inquiry practice model requires nurses to interrogate personal and contextual factors which shape nursing relationships and is posed as an alternative to nursing relationships historically understood in the context of liberal individualism and separated from any broader social or interpersonal context. Further they argue that when nurses are unaware of the relational elements (personal and contextual) influencing their actions, they are less likely to exercise effective clinical judgment and are more likely to be practicing in "relational oblivion" which makes key nursing obligations such as the obligations to be reflexive and intentional and to act at all levels to maximize health and healing impossible to meet (Doane \& Varcoe, 2007, pp. 199-200).

\section{Embrace the principles of harm reduction.}

The Canadian Nurses' Association (2011) argues that nurses have an ethical responsibility to promote health and to base their practise on available evidence. As such they argue that harm reduction strategies are essential for nurses to implement to mitigate the health-related harms associated with illicit substance use. Pauly (2008b) argues that harm reduction shifts the contextual perspective for nurses from the goal of

WITNESS "fixing" individuals to reducing harm and this can assist nurses to navigate values conflict and increase role satisfaction

\section{Resisting the Impacts of Neoliberalism Using Policy Interventions}

Numerous nurse scholars argue that nurses have an ethical responsibility to advocate for individual patients and improved access to health services. Although these advocacy activities are necessary, they are not sufficient, as nurses much also advocate further upstream for policy changes that would improve the health of marginalized groups (Browne \& Tarlier, 2008; Carnegie \& Kiger, 2009). The Canadian Nurses' Association (CNA) (2011) calls on nurses to challenge harmful policies which are neither consistent with harm reduction principles nor with the CNA Code of Ethics (2008).

There are numerous policy implications arising from understanding the socio-political context of nursing, neoliberalism and the War on Drugs. Nurses must advocate for expansion of harm reduction strategies across sectors and geography to allow for availability of a much broader range of strategies beyond the provision of opioid agonist therapy, including a range of safer drug use supplies; harm reduction education; widespread provision of overdose prevention strategies including naloxone provision; prescription of pharmaceutical opioids to people currently using toxic illicit opioids; and supervised drug consumption services such as those suggested by McNeil et al. (2015). Expansion of harm reduction services in small and rural and remote communities is particularly urgent.

Critically, nurses must join the call for the Government of Canada to decriminalize illicit psychoactive substances. A significant proportion of the stigmatization affecting people who use illicit substances arises from their criminalization. The impact of decriminalization in Portugal in 2001 has included reduced drug deaths, reduced rates of arrest and incarceration, reduced rates of HIV infection, reduced problematic and adolescent drug use and resulted in no major increases in overall substance use (Drug Policy Alliance, 2015). Further, the Global Commission on Drug Policy (2011) reports that decriminalization, in combination with alternative health-based therapeutic responses to people struggling with substance use, has reduced the burden of drug law enforcement on police, courts and prisons and reduced the overall level of problematic substance use. 


\section{Conclusion - Beginning to Bridge the Divide}

Regardless of their beliefs about substance use, I believe that most nurses want to provide excellent care based on authentic caring relationships with patients. The late psychologist Alice Miller (1991) wrote: "What is addiction, really? It is a sign, a signal, a symptom of distress. It is a language that tells us about a plight that must be understood." The gap between nurses' understanding of problematic substance use

\section{References}

Anda, R.F., Felitti,V.J., Walker, J., Whitfield, C.L., Bremner, J.D., Perry, B.D., Dube, S.R., \& Giles, W.H. (2006). The enduring effects of abuse and related adverse experiences in childhood. A convergence of evidence from neurobiology and epidemiology. European Archives of Psychiatry and Clinical Neuroscience. 56 (3), $174-86$.

Ahern, J., Stuber, J. \& Galea, S. (2007). Stigma, discrimination and the health of illicit drug users. Drug and Alcohol Dependence, 88 (2-3), 188-96.

Benner, P. (1994). The tradition and skill of interpretive phenomenology in studying health, illness, and caring practice. In P. Benner (Ed.), Interpretive Phenomenology: Embodiment, caring and ethics in health and illness (pp. 99 - 127). Thousand Oaks, CA: Sage.

Browne, A. \& Tarlier, D.S. (2008). Examining the potential of nurse practitioners from a critical social justice perspective. Nursing Inquiry, 15 (2), 83 - 93.

Butt, G. (2008). Stigma in the context of Hepatitis C: concept analysis. Journal of Advanced Nursing, 62 (2), $712-724$. doi. 10.1111/j.1365-2648.2008.04641.x

Canadian AIDS Society/ Canadian Harm Reduction Network. (2008). Learning From Each Other: Enhancing Community Based Harm Reduction Programs and Practices in Canada. Retrieved from http://www.canadianharmreduction.com/pro ject/pdf/final_report_en.pdf and the role it plays in the lives of people who have survived trauma is wide but therein lies the transformative potential of the recommendations for change - to learn to see substance use as a diagnostic clue of what lies below the surface and not as a disease, an unhealthy choice or a moral failing. Nurses must critically reflect upon and actively resist the powerful neoliberal influences that impede deeper, more humane understandings of people who use substances in our care.

Canadian Centre on Substance Abuse (2014). Trauma-Informed Care Toolkit. Retrieved from http://www.ccsa.ca/Resource\%20Library/C CSA-Trauma-informed-Care-Toolkit-2014en.pdf

CNA. (2008). Code of Ethics for Registered Nurses. Retrieved from http://www.cnaaiic.ca/en/download-buy/nursing-ethics

CNA. (2011). Harm reduction and currently illegal drugs: Implications for nursing policy, practice, education and research. Retrieved from https://www.cnaaiic.ca/ /media/cna/page-content/pdfen/harm reduction_2011_e.pdf

Carnegie, E. \& Kiger, A. (2009). Being and doing politics: on outdated model or $21^{\text {st }}$ century reality? Journal of Advanced Nursing 65(9), 1976 - 1984. doi. $10.1111 / \mathrm{j} .1365 .2648 .2009 .05084 . \mathrm{x}$

Carriere, G. (2008). Linking women to health and wellness: Street outreach takes a population health approach. International Journal of Drug Policy, 19 (3), 205 - 210.

Carter, C. (2013). The harm reduction debate: Political expediency versus progress. Retrieved from Canadian Drug Policy Coalition at http://drugpolicy.ca/blog/2013/07/the-harmreduction-debate-political-expedience-vsprogress/

Clay, R. (2007). Substance abuse and mental health services administration news. July/August 2006, 15 (4). Retrieved from www.samhsa.gov/samhsa_news/volumexv_ 4/article4.htm 
College of Physicians and Surgeons of Ontario. Avoiding abuse, achieving a balance: Tackling the opioid public health crisis. September 8 2010, Retrieved from http://cpso.on.ca/uploadedFiles/policies/posi tions/Opioid\%20report\%20final.pdf

Cosden, M., Larsen, J.L., Donahue, M.T. \& NylandGibson, K. (2015). Trauma symptoms for men and women in substance abuse treatment: A latent transition analysis. Journal of

Doane, G. H... \& Varcoe, C. (2007). Relational practice and nursing obligations. Advances in Nursing Science, 30(3), $192-205$.

Doane, G. H. \& Varcoe, C. (2015). How to Nurse: Relational Inquiry with Individuals and Families in Changing Health and Health Care Contexts. Wolters Kluwer/Lippincott Williams \& Wilkins, Philadelphia PA.

Drug Policy Alliance. (2015). Drug Decriminalization in Portugal: A HealthCentred Approach. Retrieved from https://www.drugpolicy.org/sites/default/file s/DPA_Fact_Sheet_Portugal_Decriminalizat ion_Feb2015.pdf

Fontana, J. S. (2004). A methodology for critical science in nursing. Advances in Nursing Science, 27 (2), 93 - 101.

Ford, R. (2010). An analysis of nurses' views of harm reduction measures and other treatments for the problems associated with illicit drug use. Australian Journal of Advanced Nursing, 28 (1), 14-24.

Ford, R. (2011). Interpersonal challenges as a constraint on care: The experience of nurses' care of patients who use illicit drugs. Contemporary Nurse, 37 (2), 241 - 252.

Friere, P. (1970). Pedagogy of the Oppressed. (M. Ramos, trans.). New York: Continuum.

Giordano, A.I., Prosek, E.A., Stamman, J., Callahan, M., Loseu, S., Bevly, C.M...Chadwell, K. (2016). Addressing trauma in substance abuse treatment. Journal of Alcohol and Drug Education, 60 (2), 55 - 71.
Global Commission on Drugs. (2011). War on Drugs: Report of the Global Commission on Drug Policy. Retrieved from http://www.globalcommissionondrugs.org/w pcontent/uploads/2012/03/GCDP_WaronDru gs_EN.pdf

Gomes, T., Mamdani, M.M., Dhalla, I.A., Cornish, S. \& Paterson, J.M. (2014). The burden of premature opioid-related mortality. Addiction, 109 (9), 1482-1488. doi:10.1111/add.12598

Gustafson, D., Goodyear, L. \& Keough, F. (2008). When the dragon's awake: A needs assessment of people injecting drugs in a small urban centre. International Journal of Drug Policy, 19, 189 - 194.

Hardill, K. (2011). Below the radar: An exploration of substance use in rural Ontario. Unpublished report. Advanced Clinical Practice Fellowship, Registered Nurses' Association of Ontario.

Harling, M.R. \& Turner, W. (2011). Student nurses' attitudes to illicit drugs: A grounded theory study. Nurse Education Today, 32 (2012), 235 - 240. doi: 10.1016/j.nedt.2011.05.002.

Harris, M. (2009). Injecting, infection, illness: Abjection and Hepatitis C stigma. Body Society, 15, 33-51.

Harvey, S., Schmied, V., Nicholls, D. \& Dahlen, H. (2015). Hope amidst judgement: the meaning mothers accessing opioid treatment programmes ascribe to interactions with health services in the perinatal period. Journal of Family Studies, 21 (3), 282 - 304. doi.org/10.1080/13229400.2015.1110531.

Jackson, L., Parker, J., Dykeman, M., Gahagan, J., \& Karabanow, J. (2010). The power of relationships: Implications for safer and unsafe practices among injection drug users. Drugs: Education, Prevention and Policy, 17 (3), $189-204$.

Joinson, C. (1992). Coping with compassion fatigue. Nursing, 22 (4), 118 - 121.

Kearns, R., Dyck, I \& Robinson, K. (1996). Cultural safety, biculturalism and nursing education 
in Aotearoa/New Zealand. Health and Social Care in the Community, 4 (6), $371-380$.

Klinic Community Health Centre. (2013). TraumaInformed: The Trauma Toolkit. Retrieved from http://trauma-informed.ca/wpcontent/uploads/2013/10/Traumainformed_Toolkit.pdf.

Labonte, R. \& Stuckler, D. (2016). The rise of neoliberalism: how bad economics imperils health and what to do about it. Journal of Epidemiology and Community Health, 70, 312 - 318. doi: 10.1136/jech-2015-206295,

Lang, K., Neil, J., Wright, J., Dell, C. A., Berenbaum, S., \& El-Aneed, A. (2013). Qualitative investigation of barriers to accessing care by people who inject drugs in Saskatoon, Canada: Perspectives of service providers. Substance Abuse Treatment, Prevention and Policy, 8 (35), 1-11. Retrieved from http://www.substanceabusepolicy.com/conte $\underline{\mathrm{nt} / 8 / 1 / 35}$

Lawrence, S. \& Williams, T. (2006). Swallowed up: Drug couriers at the borders of Canadian sentencing. University of Toronto Law Journal, 56: 285 - 332.

Lloyd, C. (2010). Sinning and Sinned Against: The Stigmatisation of Problem Drug Users. August 2010. Retrieved from http://www.ukdpc.org.uk/publication/sinnin g-sinned-against-stigmatisation-problemdrug-users/

McCutcheon, J. \& Morrison, M. (2014). Injecting on the Island: A qualitative exploration of the service needs of persons who inject drugs in Prince Edward Island, Canada. Harm Reduction Journal, 11 (10), 1 - 11. doi:10.1186/1477-7517-11-10.

McNeil, R., Kerr, T., Pauly, B., Wood, E. \& Small, W. (2015). Advancing patient-centred care for structurally vulnerable drug-using populations: A qualitative study of the perspectives of people who use drugs regarding the potential integration of harm reduction interventions into hospitals. Addiction, 111, 685 - 694. doi: 10.1111/add.13214.
Miller, A. (1991). Breaking Down the Wall of Silence: The Liberating Experience of Facing Painful Truth. New York City, NY. Dutton Books.

Monks, R., Topping, A. \& Newell, R. (2012). The dissonant care management of illicit drug users in medical wards, the views of nurses and patients: A grounded theory study. Journal of Advanced Nursing, 69 (4), 935 946. doi: 10.1111/j.13652648.2012.06088.x.

Moore, D. \& Fraser, S. (2006). Putting at risk what we know: Reflecting on the drug-using subject in harm reduction and its political implications. Social Science and Medicine, 62, 3035 - 3047. doi: 10.1016/j.socscimed.2005.11.067.

Morgan, B. (2014). Nursing attitudes toward patients with substance use disorders in pain. Pain Management Nursing, 15 (1), 165 - 175. doi.org/10.1016/j.pmn.2012.08.004.

Neale, J., Tompkins, C. \& Sheard, L. (2008). Barriers to accessing generic health and social care services: A qualitative study of injecting drug users. Health and Social Care in the Community, 16 (2), 147-54.

Pauly, B. (2008a). Harm reduction through a social justice lens. International Journal of Drug Policy, 19, 4-10. doi: 10.1016/j.drugpo.2007.11.005.

Pauly, B., (2008b). Shifting moral values to enhance access to health care: Harm reduction as a context for ethical nursing practice. International Journal of Drug Policy, 19 (3), $195-204$. doi:10.1016/j.drugpo.2008.02.009

Pauly, B., Goldstone, I., McCall, J. Gold, F. \& Payne, S. (2007). The ethical, legal, social context of harm reduction. Canadian Nurse, 103 (8), $19-23$.

Pauly, B., McCall, J., Browne, A, Parker, J. \& Mollison, A. (2015). Toward cultural safety: Nurse and patient perceptions of illicit substance use in a hospitalized setting. Advances in Nursing Science, 38(2), 121 135. doi: 10.1097/ANS.0000000000000070. 
Peckover, S. \& Chidlaw, R.G. (2007). Too frightened to care? Accounts by district nurses working with clients who misuse substances. Health and Social Care in the Community, 15, 238 -245 .

Peterson, G., Jackson, S. \& Fitzmaurice, K. (2007). Harm minimization strategies: Opinions of health professionals in rural and remote Australia. Journal of Clinical Pharmacy and Therapeutics, 32, $497-504$.

Ramsden, I. (2000). Cultural safety/Kawa Whakaruruhau ten years on: A personal overview. Nursing Praxis New Zealand, 15 (1), $4-12$.

RNAO. (2015). Engaging clients who use substances. Retrieved from http://rnao.ca/sites/rnaoca/files/Engaging_Clients_Who_Use_Substa nces 13 WEB.pdf

Sandford, A., Donahue, M. \& Cosden, M. (2014).

Consumer perceptions of trauma assessment and intervention in substance abuse treatment. Journal of Substance Abuse Treatment, 47, 233 - 238. Doi: 10.1016/j.jsat.2014.05.001.

Smye, V., Browne, A., Varcoe, C. \& Josewski, V. (2011). Harm reduction, methadone maintenance treatment and the root causes of health and social inequities: An intersectional lens in the Canadian context. Harm Reduction Journal, 8:17, 1-12.

Thorne, S. (2008). Interpretive Description. Walnut Creek, CA: Left Coast Press, Inc.

Thorne, S., Reimer Kirkham, S., \& MacDonaldEmes, J. (1997). Interpretive description: A non-categorical qualitative alternative for developing nursing knowledge. Research in Nursing and Health, 20: $169-177$.

Thorne, S., Reimer Kirkham, S. \& O'Flynn-Magee, K. (2004). The analytic challenge in interpretive description. International Journal of Qualitative Methods. 3 (1): 1-11.

Wise-Harris, D., Pauly, D., Kahan, D., Tan de Bibiana, J., Hwang, S. W. \& Stergiopoulous, V. (2016). "Hospital was the only option": Experiences of frequent emergency department users in mental health.
Administration and Policy In Mental Health, 2016 Mar 9, doi: 10.1007/s10488-016-07283 